\title{
Viscoelastic behaviour of green wood across the grain. Part I. Thermally activated creep tests up to $120{ }^{\circ} \mathrm{C}$
}

\author{
Joëlle PASSARD, Patrick PERRÉ* \\ Laboratory of Wood Science (LERMAB), UMR 1093 INRA/ENGREF/Université H. Poincaré Nancy 1 ENGREF, \\ 14 rue Girardet, 54042 Nancy Cedex, France
}

(Received 31 July 2004; accepted 31 May 2005)

\begin{abstract}
In this work, we present an improved experimental set-up capable of performing creep tests on water-saturated samples up to $120{ }^{\circ} \mathrm{C}$. A typical test consists of three phases : a linear increase in temperature up to the desired value, a plateau at this temperature level during $15 \mathrm{~h}$ and a cooling period. For each species (spruce and oak) and each direction across the grain (radial and tangential), a whole set of creep tests is available, at different plateau temperatures : $65^{\circ} \mathrm{C}, 85^{\circ} \mathrm{C}, 105{ }^{\circ} \mathrm{C}$ and $120{ }^{\circ} \mathrm{C}$. The modulus of elasticity (MOE) measured at room temperature on green wood confirms expected results: it is almost twice as high in radial direction and more than twice as high for oak: average values of 253 and $119 \mathrm{MPa}$ for Spruce and 687 and $398 \mathrm{MPa}$ for Oak in radial and tangential direction respectively. In the case of oak, the MOE of tension wood can also be distinguished from normal wood: its modulus is smaller in spite of a higher density. The creep tests reveal the importance of the temperature level on the thermal activation: the apparent MOE might loss more than two orders of magnitude after a test at $120^{\circ} \mathrm{C}$. This effect is more pronounced and starts at lower temperature values for oak than for spruce while its is almost the same, in relative value, in radial and tangential directions.
\end{abstract}

wood / viscoelastic / Kelvin's element / thermal activation / model / identification / inverse method

Résumé - Comportement viscoélastique du bois vert dans le plan transverse. Partie $\mathrm{I}$ : tests de fluage thermo-activés jusqu'à $120{ }^{\circ} \mathrm{C}$. Dans ce travail, nous présentons un dispositif amélioré permettant d'effectuer des essais de fluage jusqu'à $120^{\circ} \mathrm{C}$ sur des échantillons de bois saturés. Un test typique comporte trois phases : une montée linéaire en température, un palier de $15 \mathrm{~h}$ à la température voulue et une phase de refroidissement. Pour chaque essence (épicéa et chêne) et chaque direction dans le plan transverse (radiale et tangentielle) un jeu complet d'essais est disponible pour quatre températures de palier : $65^{\circ} \mathrm{C}, 85^{\circ} \mathrm{C}, 105^{\circ} \mathrm{C}$ et $120{ }^{\circ} \mathrm{C}$. Le module d'élasticité mesuré à température ambiante confirme les résultats escomptés : il est deux fois plus grand en direction radiale qu'en direction tangentielle et plus de deux fois plus grand pour le chêne : valeurs moyennes égales à 253 et 119 MPa pour l'épicéa et 687 et 398 MPa pour le chêne selon les directions radiale et tangentielle respectivement. Par ailleurs, le bois de tension a pu être distingué du bois normal : il est moins rigide en dépit d'une infra densité plus élevée. Les essais de fluage montrent l'effet de la température sur l'activation thermique : la rigidité apparente peut perdre deux ordres de grandeur après un test à $120^{\circ} \mathrm{C}$. Cet effet est plus marqué et s'exprime à plus basse température pour le chêne que pour l'épicéa, tandis que qu'il est à peu près identique, en valeur relative, pour les directions radiale et tangentielle.

bois / viscoélastique / élément de Kelvin / activation thermique / modélisation / identification / méthode inverse

\section{INTRODUCTION}

Wood is a remarkable forest product omnipresent in human societies through the ages and all over the world. Its biological origin confers to this material a particular position among other materials, like for instance metals, concrete, polymers. Indeed extracted from trees, which are able to adapt to quite different ecosystems, wood is a sustainable raw material characterised by an important variability of its properties. Consequently in order to optimise its utilisation, this material is submitted to a large range of transformation techniques (drying, thermoforming, thermal treatment, re-built wood...). The development of those techniques induces deeper and deeper knowledge in wood sciences. The field of investigation is huge and involves different disciplines such as biology, chemistry, physics and applied mathematics. However, it may be noticed that for any processes temperature and moisture content of wood are both fundamental parameters in order to control and improve the transformed material performance.

The subject of this paper is focused on physics of wood, especially on wood viscoelastic properties thermally activated. Numerous scientific papers have been devoted to this sensitive question since several decades $[15,21,23,24]$. In addition to these well-known papers, numerous papers continue to appear in this field which remains very active [1-3, 11, 25]. Different and complementary methods have been used to characterise the effect of temperature and/or moisture content on the behaviour

\footnotetext{
* Corresponding author: perre@engref.fr
} 
of wood or its components (cellulose, hemicellulose, lignins). Usually the methods chosen to separate the effects of time and temperature (or moisture content) are all based on harmonic tests: dynamic mechanical measurements $[6,13]$ or dielectric measurements [16]. In those both cases, the loss factor, which characterises the material damping properties, is determined as a function of the following parameters (input signal frequency, temperature and moisture content of the sample). The results of this kind of investigation are quite simple to analyse, provided the experimental determination of the loss factor is relevant. That last condition has to be checked carefully. However several problems exist, which reduce significantly the possible range of frequencies, temperature or moisture content levels. Indeed, such sophisticated experimental methods do not allow both temperature and moisture content to be controlled over a large range of variation. Furthermore, in case of harmonic test the frequency interval is very limited because of the mechanical features of the system. Considering dielectric tests, the moisture content level is quite limited due to certain system physical properties.

In general it is even more difficult to reach regions with both high temperature levels and high humidity levels. To our knowledge, papers proposing measurements of saturated samples over $100{ }^{\circ} \mathrm{C}$ are very seldom $[4,5,20,22]$. Differencial Scanning Calorimetry (DSC) is able to produce information over much larger range of temperature and humidity levels [12, $13,17,27]$. Nevertheless the scalar information gained by this apparatus is not able to capture the effects of wood morphology (constituents at the cell wall and anatomical pattern). In addition this method is not suitable to analyse the time-temperature dependency: the softening or glass transition temperature values determined by DSC are systematically lower than those obtained by mechanical tests. Because of all these reasons, scientists continue to use simpler but reliable methods, such as creep tests and simple mechanical tests at constant deformation rate, or to imagine innovative devices [3-5, 7, 8, 11, 25].

The present work, which uses creep tests at increasing temperature, must be placed in the continuation of a former paper [20]. Its main objective is to characterise the thermally activated viscoelastic behaviour of wood by laying down the principle of an inverse method developed to identify the Kelvin's elements of a constitutive model. The paper is structured in two parts: the first one is devoted to the experimental results, gained on two different species in radial and tangential directions and the second one proposes a new identification procedure able to deal simultaneously with several tests having different timetemperature histories. This approach is based on observation and relevant analysis of raw experimental data.

Therefore the first part of this article is focused on the description of the experimental set-up. Referring to the document of Perré and Aguiar [20], we point out the improvements carried out on the device. We also stress on the configuration of the mechanical tests (cantilever system) and on the care brought to wood specimen selection and sample geometry. In order to study the dependence of wood viscoelastic behaviour on temperature, a set of bending creep tests are proposed at different temperature levels ranging from room temperature up to $120^{\circ} \mathrm{C}$. Spruce (Picea abies) and oak (Quercus), respectively conifer and broad-leave species were chosen for this study. The samples are tested along the two transverse material directions,

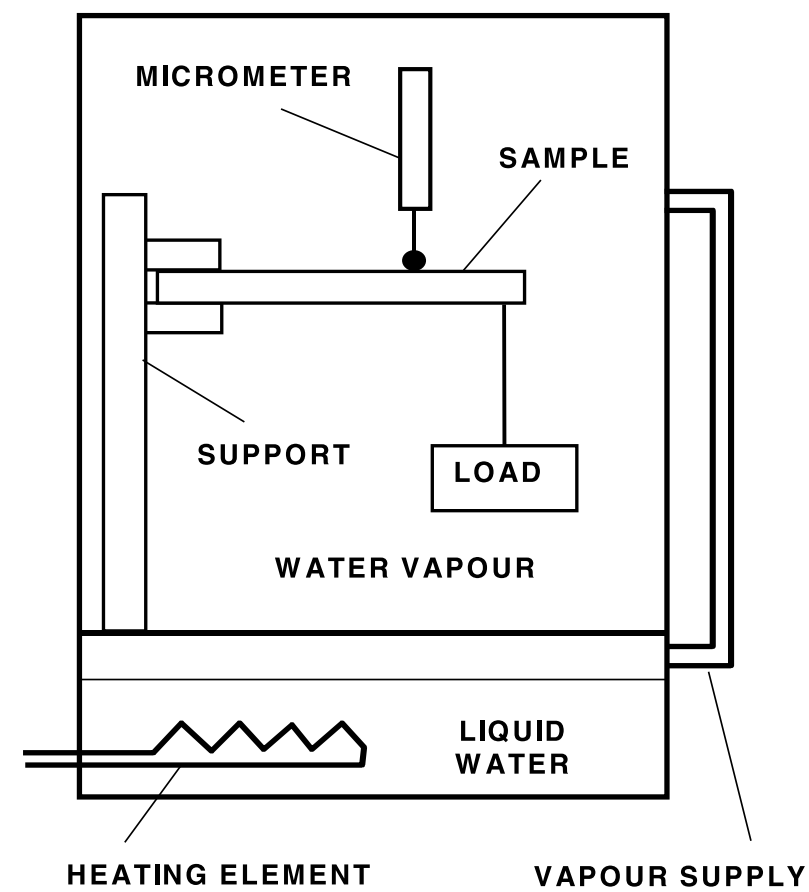

Figure 1. Diagram of the experimental device.

radial and tangential. Those data are completed by measurement of the specific density and of the Young modulus at room temperature at the beginning of each test. Finally, a set of experimental data is selected and presented for each species, each direction in the transverse plane ( $\mathrm{R}$ and $\mathrm{T}$ ) and each level of the plateau temperature. These sets of data will be used in part II in the identification procedure.

\section{MATERIALS AND METHOD}

\subsection{Experimental device}

Above $100{ }^{\circ} \mathrm{C}$, the only way to keep the specimen in green state is to proceed under pressure, keeping vapour pressure at its saturated value. This was obtained in our experimental set-up with the aid of an autoclave. The device used in the present work is able to maintain saturated conditions up to $132^{\circ} \mathrm{C}$ for a chamber volume of about 100 litres (diameter $=45 \mathrm{~cm}$, height $=62 \mathrm{~cm})[20]$. Accordingly, creep tests can be carried out under fairly high-temperature and high-pressure steam conditions. Under such drastic conditions, bending tests of small wood sample with a cantilever system under static loading are the easiest tests to be performed (Fig. 1). In order to check the measurement reproducibility or to perform comparison, two samples are tested simultaneously. LVDT sensors measure the sample deflection. A typical test performed with our device comprises three stages:

- the temperature increases from room temperature up to the desired temperature, (constant rate of $0.12{ }^{\circ} \mathrm{C} \cdot \mathrm{min}^{-1}$ );

- the temperature is maintained at this level for about $10 \mathrm{~h}$;

- the device is finally cooled down to the room temperature.

Because the temperature level is obtained by heating the water tank situated at the bottom of the autoclave, the sample and its environment are heated by enthalpy transfer (water liquefaction), which ensures saturated conditions. In the initial experimental set-up [20], the chamber 

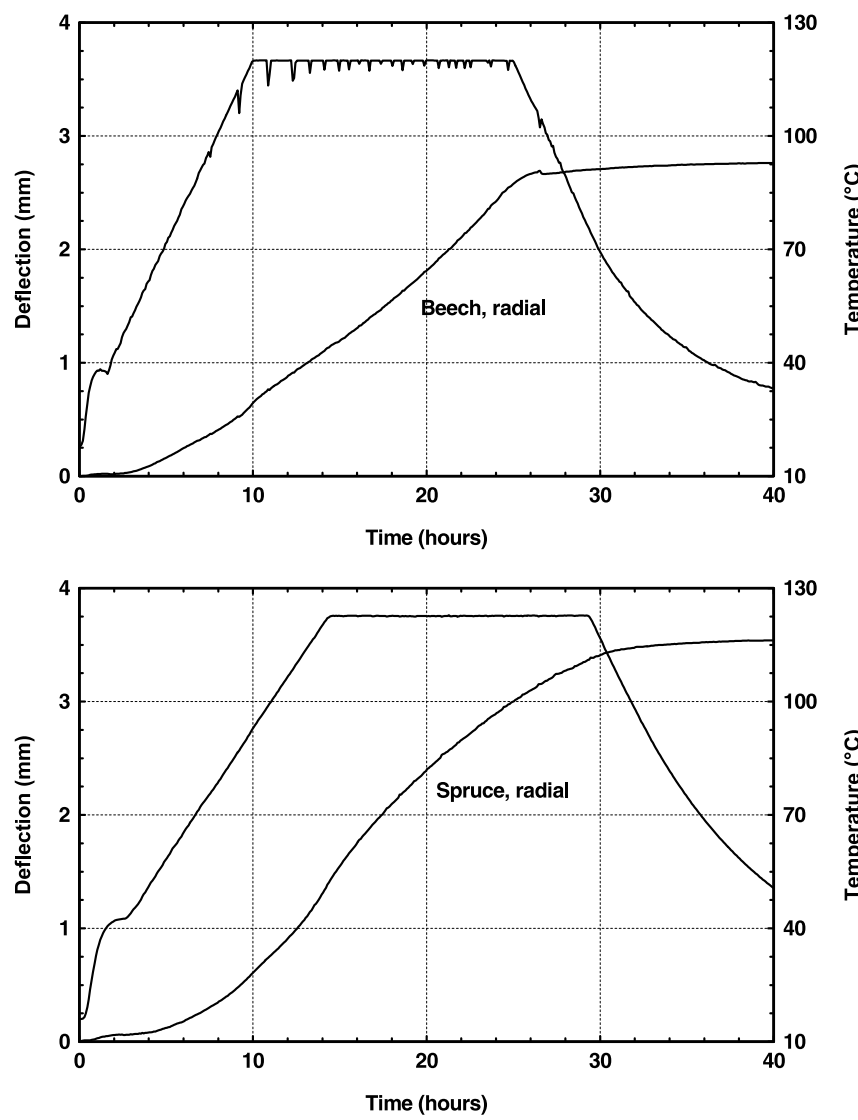

Figure 2. Example of experimental raw data before (top, beech, load = $976 \mathrm{~g}, \mathrm{~h}=19.5 \mathrm{~mm}$ ) and after (bottom, spruce, load $=409 \mathrm{~g}, \mathrm{~h}=$ $21.8 \mathrm{~mm}$ ) the modification of the device. Temperature fluctuations are significantly reduced and the sample which is placed in water is not submitted anymore to capillary forces.

was full of water at the end of the experiment when the test lasted more than about $30 \mathrm{~h}$. Such a flux of water required regular refilling of the boiler, which induced sudden temperature perturbations. In the present work, these defaults have been eliminated by insulating the experimental chamber. In addition each specimen is now placed in a container full of water to disregard mechano-sorptive effects and capillary forces during the cooling stage and to stabilise the sample temperature. A small $\mathrm{K}$ thermocouple, $0.5 \mathrm{~mm}$ in diameter, in inserted inside a small hole drilled in the sample. The value collected during the test by this thermocouple accounts for the thermal inertia of the whole apparatus and will be utilised as the experimental temperature for all plots and for the identification procedure (part II of this article).

The first graph of Figure 2 depicts the temperature perturbations due to the sudden cold water supply in the tank before the insulation improvement. That happened quite often during the plateau at elevated temperature and particularly at $120^{\circ} \mathrm{C}$. On the second graph, the experimental chamber is insulated and the temperature perturbations disappeared. However at the beginning of the rising temperature period, the over-shoot is more pronounced with the new configuration. The more important inertia of the insulated chamber and the water containers are responsible for this phenomenon. One can also notice that the better insulation significantly reduced the cooling rate during the cooling period. Concerning the sample deflection, three stages appear clearly on the second graph:

- a period at increasing creep rate, due the linear increase of temperature;

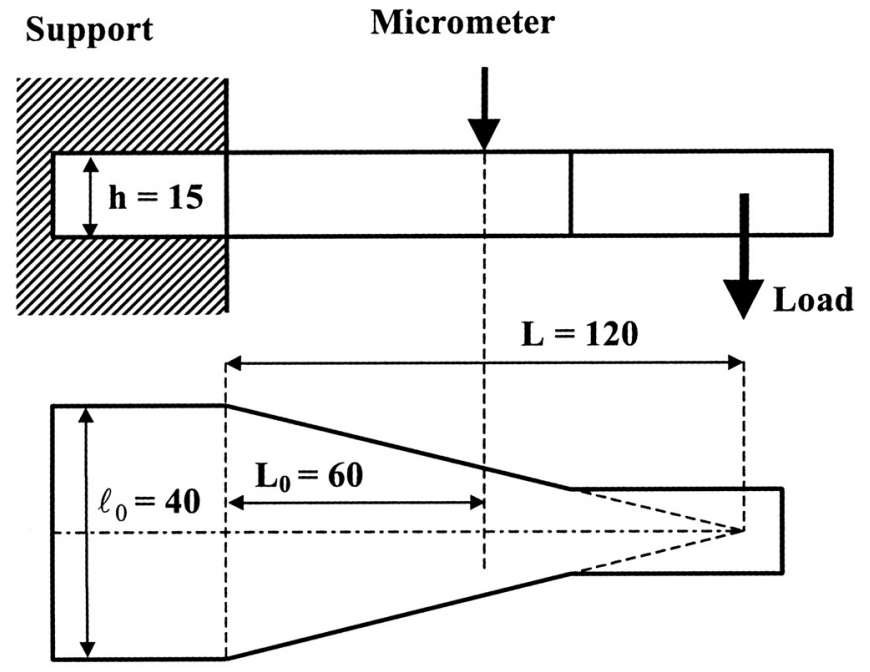

Figure 3. Sample geometry used in the present work.

- a classical creep period, during the temperature plateau;

- a drastic reduction of the creep rate as soon as the sample temperature is reduced.

\subsection{Specimens and measurement}

\subsubsection{Bending test with cantilever system}

As mentioned above, creep experiments with cantilever system are performed in this study. This configuration is very simple to implement but the interpretation requires a careful and tricky data analysis (part II of this article). In addition, shear deformation and sample collapse at clamp represent two possible disturbing effects for the measurement of the elastic (Young modulus) and viscoelastic properties. Neglecting these effects underestimates the material rigidity. Depending on the mechanical configuration, those secondary effects may be significant, especially for anisotropic materials like wood.

At first let us neglect these disturbing effects. Therefore the question of an iso-stressed sample submitted to a simple bending test is treated in the same way as in previous works [7, 20]. It is assumed that the curvature of the elastic line only is responsible for the deformation. The shape of the sample ("iso-stressed"), as exhibited in Figure 3, allows the relationship between the deflection and the load to be easily computed: due to the linearly decreasing inertia of the beam up to the load position, the curvature of the bending sample is constant. Consequently, the stress and the curvature $\rho$ are assumed to be constant throughout a constant depth area of the sample. By assuming small displacements, the deflection is obtained as follows:

$$
H=\frac{6 P L_{0}^{2} L}{\ell_{0} h^{3} E}
$$

where $\ell_{0}$ : beam width at clamp (m); $h$ : thickness of the beam $(\mathrm{m})$; $L$ : distance of the load application point from the support (m); $L_{0}$ : distance of the deflection measuring point from the support (m); $P$ : load $(\mathrm{N}) ; E$ : modulus of elasticity (MOE) or apparent modulus of elasticity (AMOE) (Pa).

Measuring $H$ allows the modulus of elasticity (MOE) or the apparent modulus of elasticity (AMOE) to be determined via equation (2):

$$
E=\frac{6 P L_{0}^{2} L}{l_{0} h^{3} H} .
$$


$-\mathbf{h} / \mathbf{2} \quad\left|\sigma_{\max }\right|=\frac{6 P L_{0}}{\ell_{0} h^{2}}$

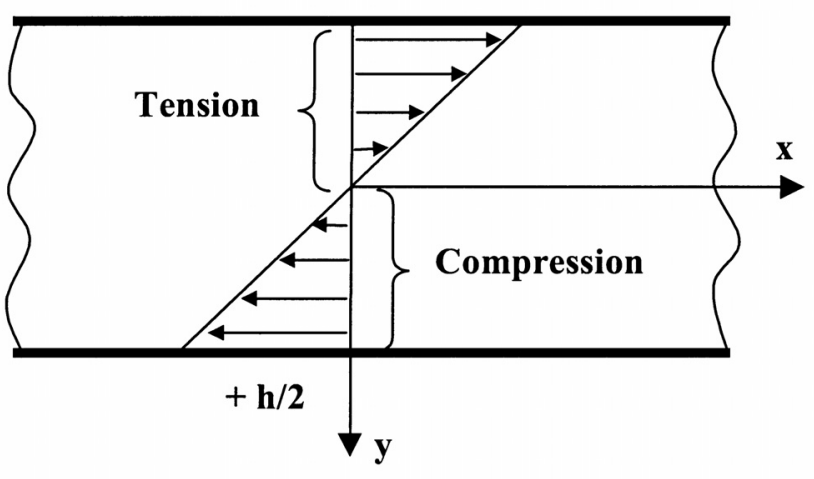

Figure 4. Normal stress distribution assumed linear throughout the thickness of the sample.

If $P, H, L_{0}, L, h$ and $\ell_{0}$ are expressed respectively in Newton and meters, both modulus MOE and AMOE are expressed in MPa (N/ $\mathrm{mm}^{2}$ ). The MOE is determined by the value of $H$ gathered at room temperature before the creep test and the time evolution of the AMOE is obtained by using the deflection measured at time $\mathrm{t}, H(\mathrm{t})$, in equation (2).

Above the neutral axis, the sample is submitted to tension, while it is submitted to compression below the neutral axis. Yet, it is well known that wood behaves differently in compression and in tension [14]. Nevertheless, in the case of small stress levels (compared to the admissible stress level), the normal stress distribution may be assumed linear (Fig. 4) and does not change the above deflection formula (Eqs. (1) and (2)). Such a linear profile is assumed throughout this work. In that case the maximum value of normal stress is obtained at the sample surface $(y= \pm h / 2)$ :

$$
\left|\sigma_{\max }\right|=\frac{6 P L_{0}}{\ell_{0} h^{2}} .
$$

Note that the stress level is independent of the mechanical properties of the material. It depends only on the load and on the sample geometry. In the following, the value of $\sigma_{\text {max }}$ determined using equation (3) will allow the stress level of tests carried on different specimens of wood to be compared.

\subsubsection{Influence of wood anisotropy on bending test}

The shear strain, which is a secondary effect for bending tests, cannot be always neglected. Only a four-point bending test allows the elastic modulus to be accurately measured within the constant bending moment region where the shear stress is zero [26].

Considering the other types of bending tests, the outcomes of normal and shear stresses are treated separately. The material response is supposed to be a linear function of stress. Thus the total response to the two different kinds of stresses is the sum of each contribution. The influence of shear stress on the deflection can be evaluated by the following formula [26]:

$$
H_{t o t}=\frac{6 P L_{0}^{2} L}{\ell_{0} h^{3} E}\left(1+\alpha \frac{h^{2}}{L^{2}} \frac{E}{G}\right) .
$$

Equation (4) says that neglecting the effect of the shear stress leads to an underestimation of the Young's modulus. The coefficient $\alpha$
Table I. Anisotropy values of the elastic properties noticed for three species of wood (after Kollman and Côté, 1968). $\rho^{*}$ stands for the specific gravity: ratio of wood density over water density.

\begin{tabular}{lcccc}
\hline Species & $\rho *$ & $E_{\mathrm{L}} / E_{\mathrm{T}}$ & $E_{\mathrm{L}} / \mathrm{G}_{\mathrm{TL}}$ & $E_{\mathrm{R}} / G_{\mathrm{LR}}$ \\
\hline Balsa wood & 0.10 & 62 & 31 & 1.1 \\
Spruce & 0.43 & 41 & 27 & 1.2 \\
Oak & 0.67 & 13 & 7.4 & 1.7 \\
\hline
\end{tabular}

depends on the type of bending test and on the specimen shape. In the case of a cantilever beam with the deflection being measured at the loading point, the coefficient $\alpha$ is equal to $3 / 8$ for a parallelepiped beam [26]. Using our specific sample geometry, we derived the following analytical expression from the approach proposed by Timoshenko:

$$
H_{t o t}=\frac{6 P L_{0}^{2} L}{\ell_{0} h^{3} E}\left(1+\frac{h^{2}}{4 L_{0}^{2}} \ln \left(\frac{L}{L-L_{0}}\right) \frac{E}{G}\right) .
$$

Using equation (5), the coefficient $\alpha$ appearing in equation (4) may be calculated with the sample dimensions as specified in Figure 3. The obtained value is close to 0.2 . Notice that the length used in the formula is $L_{0}$ (length at which the deflection is measured) rather than $L$ (beam length).

Due to its anisotropy, the quotient $E / G$ may be very important for wood, especially when $E$ is measured in the longitudinal direction. Some data by Kollman and Côté ([14], pp. 294-295) illustrate this statement for different wood species equilibrated at about $10 \%$ of moisture content (Tab. I).

This table proves that the anisotropy ratio $E_{\mathrm{L}} / E_{\mathrm{T}}$ between the longitudinal and tangential directions increases as the wood density decreases. The two ratios $E_{\mathrm{L}} / G_{\mathrm{TL}}$ and $E_{\mathrm{R}} / G_{\mathrm{LR}}$ allow the shear strain effect to be evaluated in the case of a bending test respectively in the longitudinal and radial directions ${ }^{1}$ (to be used in Eq. (5)). Data of Table I highlight that the worst configuration in bending test is obtained for the longitudinal direction. The worst result is obtained for balsa wood (low density). At the opposite, bending tests performed in the transverse directions give much better results, oak being the worst due to its high density, with a $E_{\mathrm{R}} / G_{\mathrm{LR}}$ value equal to 1.7 . Note that the results would be even better for tests in the tangential direction.

Anyway decreasing the geometrical ratio $h / L$ may reduce significantly the shear stress influence. Considering the sample dimensions as mentioned in Figure 3, the Young modulus would be underestimated by $1 \%$ for the best configuration (spruce in radial direction) and by $30 \%$ in the worst one (balsa in longitudinal direction). In the present work spruce and oak species are tested in the radial and tangential directions. According to our set of measurements, the underestimation of elastic properties lies in a tiny range between $1.8 \%$ and $3.2 \%$.

All those observations are only available for elastic properties of wood. In case of viscoelasticity of wood it is not obvious to evaluate the shear strength effect, especially during the thermal activation. Indeed the transition phenomena of certain wood components (amorphous cellulose, lignin and polyoses) at different values of temperature, makes the situation quite complicated. Without measuring the apparent shear modulus versus temperature one can only speculate. So, in the following work, the shear strength effect will be assumed to stay negligible throughout the creep tests.

${ }^{1}$ In this case, the longitudinal direction is assumed to be along the height of the sample. 


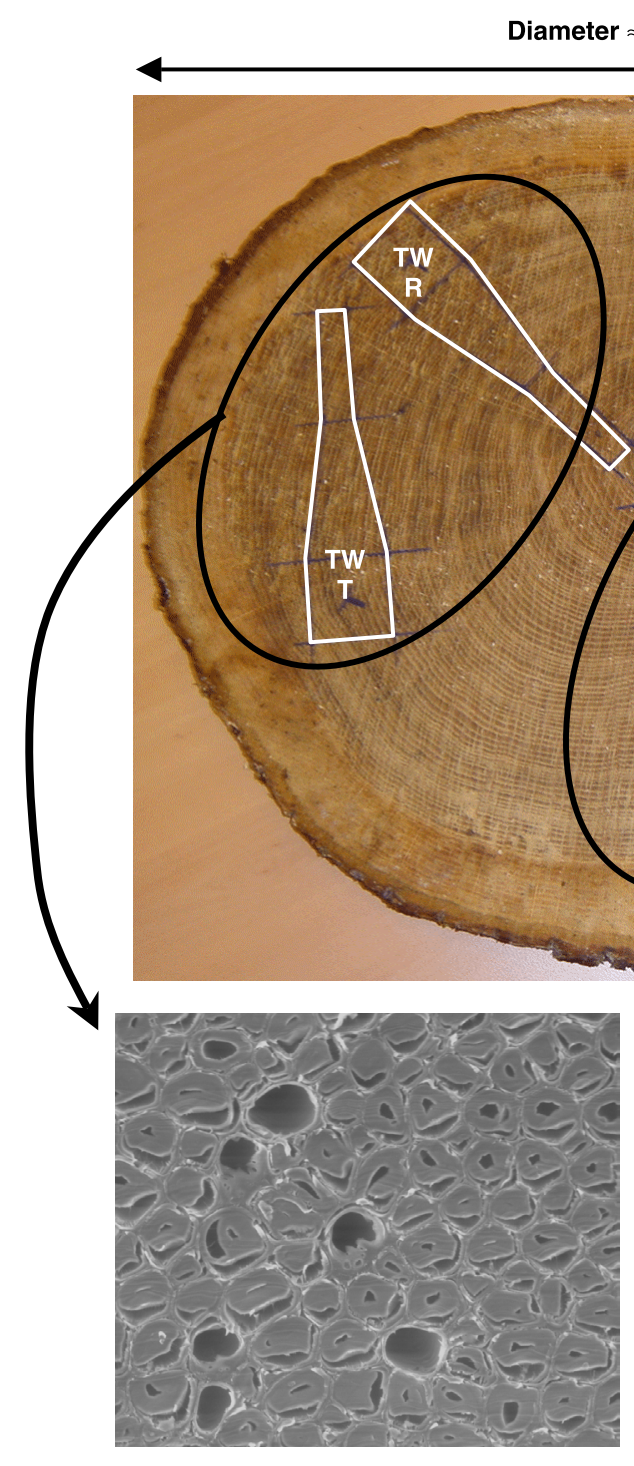

Tension wood

ameter $\approx 51 \mathrm{~cm}$

\section{政}
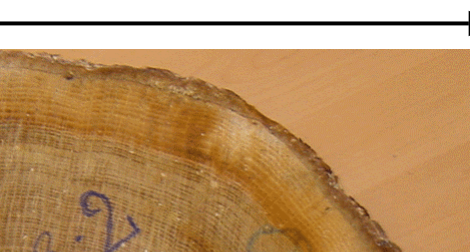

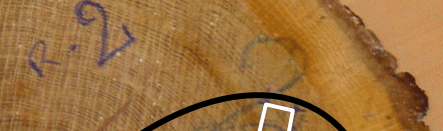

(

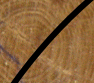

(1)
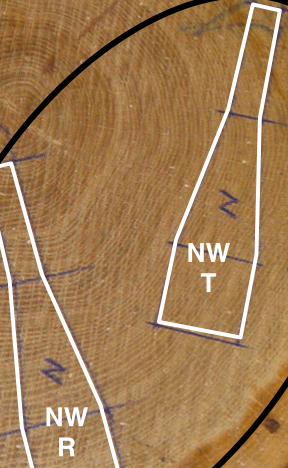

R

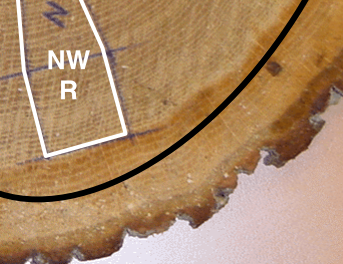

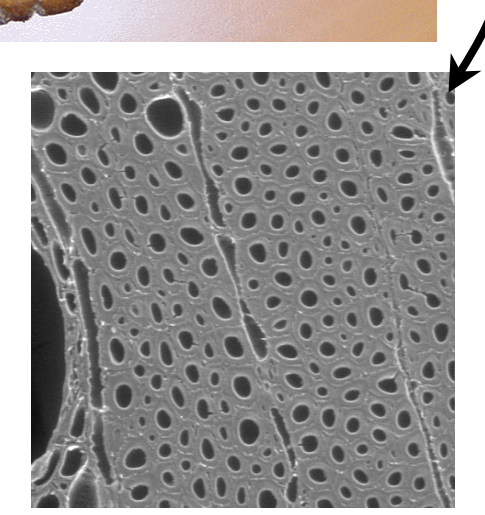

Normal wood
Figure 5. View of a disk of oak with a zone of tension wood on the left and the location where radial and tangential sample are taken (top). Microphotographs from these zones, which depict the G-layer in fibres in the tension wood zone (bottom, ESEM, P. Perré, LERMAB-ENGREF).

\subsubsection{Wood material selection}

The harvesting of wood material has been done in the region of Nancy (eastern part of France) in two different forest settlements belonging to the ENGREF (Forest School of Nancy). For both settlements the high forest system is applied.

The sampling of normal spruce wood was realised from one single tree felled in the forest settlement called "Domaine de la Sivrite", at the end of winter season in February 2002. This forest settlement is an arboretum of the ENGREF located in a typical forest of the region named "Forêt de Haye". Its soil mantel composed of silt layers above calcareous rocks is propitious for large areas of beechwood wherein spruce and other species coexist in symbiosis.

Oak wood is also extracted from only one tree, which exhibited an important zone of tension wood (Fig. 5). The tree has been cut during spring (in May 2002) in the forest settlement called "Forêt de Brin". This location is characterised by clay pans favourable to the production of oak with high quality. Notice that for both species, the sampling was carried out exclusively in heartwood.

A piece of the $\log$ has been selected in the best part of the tree and has been preserved in green state. Figure 5 illustrates the selection of iso-stress samples for radial and tangential tests from a disk of oak wood. The method of sampling was the same for spruce wood. In the particular case of oak, it may be noticed that the specimens are chosen in two zones: one considered as normal wood and the second one considered as tension wood. Furthermore prismatic specimens were selected to determine the mean basic density of spruce and oak wood. The basic density is ratio of oven-dry mass of wood over its green volume [28]. In an unique disk of oak wood, samples were numbered from 1 to 6 and 1' to 6' (Tab. II). The first series is located in the supposedly normal wood and the second in the supposedly tension wood. The order of magnitude is in a good agreement with literature data [14] and invites some remarks. Firstly, in heartwood the infra density increases from pith to bark. This trend may be more or less pronounced 
Table II. Measurements of basic density for spruce and oak wood.

\begin{tabular}{lcccc}
\hline Spruce, disk No. 1 & & & & \\
Sample number & 1 (=> pith) & 2 & 3 & 4 (=> sap) \\
Basic density $\left(\mathrm{kg} / \mathrm{m}^{3}\right)$ & 371 & 393 & 414 & 430 \\
\hline Spruce, disk No. 2 & & & & \\
Sample number & 1 ' (=> pith) & 2 & 3 & $4^{\prime}$ (=> sap) \\
Basic density $\left(\mathrm{kg} / \mathrm{m}^{3}\right)$ & 410 & 414 & 424 & 438 \\
\hline Oak, normal wood & & & & \\
Sample number & 1 (=> pith) & 2 & 3 & 4 \\
Basic density $\left(\mathrm{kg} / \mathrm{m}^{3}\right)$ & 576 & 574 & 569 & 573 \\
\hline Oak, tension $\boldsymbol{\text { wood }}$ & & & & \\
Sample number & 1 ' (=> pith) & 2 & 3 & 4 \\
Basic density $\left(\mathrm{kg} / \mathrm{m}^{3}\right)$ & 558 & 593 & 601 & 599 \\
\hline
\end{tabular}

depending on the type of wood but is observable for both species. Although this result is surprising in the case of oak, this trend is consistent here because our tree presents several sets of large annual growth rings in the outer part. As expected, the infra density is higher for tension wood than for normal wood. In order to confirm the presence of tension wood in this zone, microphotographs have been achieved using the ESEM microscope available at LERMAB. On these views, the presence of G-layer (gelatinous layer) in the fibres, typical of tension wood, becomes evident (Fig. 5, bottom).

In order to characterise the elastic properties, before each creep test the water saturated specimen is loaded suddenly at room temperature and the corresponding deflection is measured. For each species and each material direction about ten tests were carried out. In table 3, the upper and lower values of the modulus of elasticity are given for water saturated green wood in the transverse directions. The average value was chosen as representative MOE for the corresponding direction for soaked samples. Using data available in literature [14], this value allows a ratio between green wood and wood at $10 \% \mathrm{MC}$ to be computed (last column of Tab. III). Such a calculus ignores about wood variability, but the average factor, around 3, is not surprising. For example, according to Carrington (1922) quoted in ([14], p. 309) the Young moduli are affected by a factor ranging from 2 to 3 in the transverse directions from green to dry spruce wood. The correlative model proposed by Guitard [10] leads to a ratio slightly smaller (around 2.2).

For oak it might be noted that, in spite of a higher basic density, the mechanical properties of tension wood are smaller than those of normal wood. The poor adhesion of the gelatinous layer with the secondary layers or the poor mechanical behaviour of the G-layer in the transverse plane are two possible explanations for this observation.

\section{RESULTS}

\subsection{Experimental raw data}

In the paper published by P. Perré and O. Aguiar [19] all the creep tests had a plateau temperature at $120^{\circ} \mathrm{C}$. As a result, all tests have the same time-temperature itinerary. Because time and temperature effects cannot be distinguished from this unique itinerary, the Kelvin's elements fitted from these tests gave unrealistic results when used to simulate processes such as drying or steaming. In order to address this problem, the parameters of the constitutive model must be deduced from different time-temperature itineraries. Consequently, we decided
Table III. Modulus of elasticity for spruce and oak wood.

\begin{tabular}{lcccc}
\hline $\begin{array}{l}\text { Species and } \\
\text { type of wood }\end{array}$ & $\begin{array}{c}\text { MOE, green wood } \\
\text { (MPa) Average } \\
\text { (min...max) }\end{array}$ & $\begin{array}{c}\text { MOE, 10\% } \\
\text { MC (MPa) } \\
{[14]}\end{array}$ & $\begin{array}{c}\text { Relative increase } \\
\text { of ME from green } \\
\text { to 10\% }\end{array}$ \\
\hline Spruce, normal & $\mathrm{R}$ & $\mathbf{2 5 5}(208 \ldots 307)$ & 700 & 2.74 \\
wood & $\mathrm{T}$ & $\mathbf{1 1 9}(92 \ldots 154)$ & 400 & 3.36 \\
Oak, normal & $\mathrm{R}$ & $\mathbf{6 8 7}(559 \ldots 781)$ & 2190 & 3.18 \\
wood & $\mathrm{T}$ & $\mathbf{3 9 8}(347 \ldots 526)$ & 990 & 2.49 \\
Oak, tension & $\mathrm{R}$ & $\mathbf{6 0 7}(495 \ldots 711)$ & - & - \\
wood & $\mathrm{T}$ & $\mathbf{3 5 4}(292 \ldots 434)$ & - & - \\
\hline
\end{tabular}

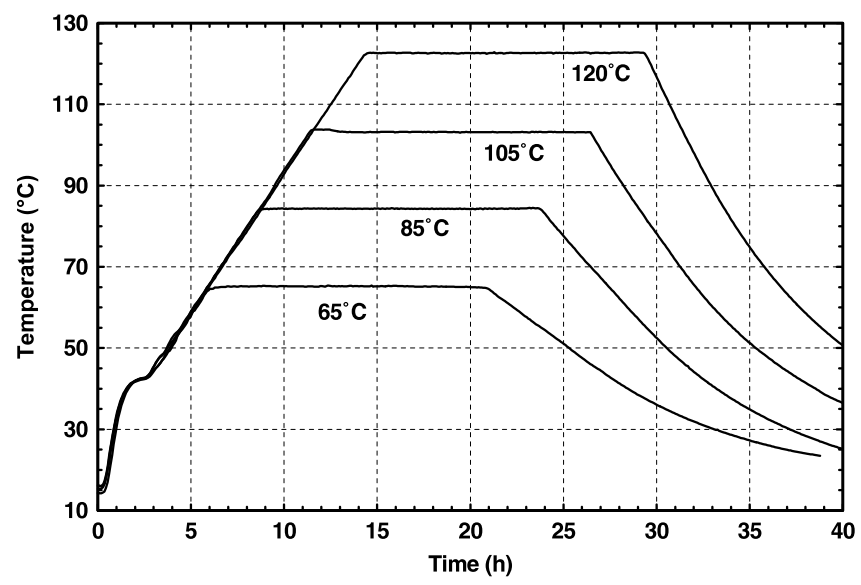

Figure 6. The temperature evolution according to our protocole at different temperature levels $\left(65^{\circ} \mathrm{C}, 85^{\circ} \mathrm{C}, 105^{\circ} \mathrm{C}\right.$ and $120^{\circ} \mathrm{C}$, constant heating rate equal to $0.12{ }^{\circ} \mathrm{C} / \mathrm{min}$ ).

Table IV. The eight test selected for Spruce : load level, sample height (h), MOE measured at room temperature on the water-saturated sample and maximum stress level in the section.

\begin{tabular}{lccccc}
\hline & $\begin{array}{c}\text { Temperature } \\
\left({ }^{\circ} \mathrm{C}\right)\end{array}$ & $\begin{array}{c}\text { Load } \\
(\mathrm{g})\end{array}$ & $\begin{array}{c}\text { Height } \\
(\mathrm{mm})\end{array}$ & $\begin{array}{c}\text { MOE } \\
(\mathrm{MPa})\end{array}$ & $\begin{array}{c}\text { Stress level } \\
(\mathrm{kPa})\end{array}$ \\
\hline Radial & 65 & 960 & 18.6 & 256 & 236 \\
& 85 & 798 & 21.0 & 208 & 157 \\
& 105 & 465 & 19.5 & 210 & 107 \\
& 120 & 409 & 21.8 & 276 & 75 \\
\hline Tangential & 65 & 591 & 18.8 & 124 & 152 \\
& 85 & 465 & 18.2 & 129 & 120 \\
& 105 & 298 & 19.0 & 154 & 72 \\
& 120 & 246 & 22.0 & 125 & 43 \\
\hline
\end{tabular}

to adopt another strategy of investigation and to carry out a series of creep tests activated at different temperature levels. All the tests were realised with a constant heating rate equal to $0.12{ }^{\circ} \mathrm{C} / \mathrm{min}$ up to the desired plateau temperature. The temperature is then maintained at this level during $15 \mathrm{~h}$. The cooling period starts with a constant decreasing rate but ends up with an exponential shape once the thermal losses are not sufficient anymore (Fig. 6). 
Table V. The eight test selected for oak: load level, sample height (h), MOE measured at room temperature on the water-saturated sample and maximum stress level in the section.

\begin{tabular}{lccccc}
\hline & $\begin{array}{c}\text { Temperature } \\
\left({ }^{\circ} \mathrm{C}\right)\end{array}$ & $\begin{array}{c}\text { Load } \\
(\mathrm{g})\end{array}$ & $\begin{array}{c}\text { Height } \\
(\mathrm{mm})\end{array}$ & $\begin{array}{c}\text { MOE } \\
(\mathrm{MPa})\end{array}$ & $\begin{array}{c}\text { Stress level } \\
(\mathrm{kPa})\end{array}$ \\
\hline Radial & 65 & 1460 & 16.9 & 770 & 442 \\
& 85 & 1460 & 17.7 & 781 & 412 \\
& 105 & 234 & 16.7 & 705 & 72 \\
& 120 & 234 & 16.4 & 661 & 76 \\
\hline Tangential & 65 & 1164 & 16.9 & 414 & 351 \\
& 85 & 1164 & 18.6 & 364 & 303 \\
& 105 & 190 & 15.7 & 399 & 66 \\
& 120 & 190 & 16.3 & 526 & 64 \\
\hline
\end{tabular}
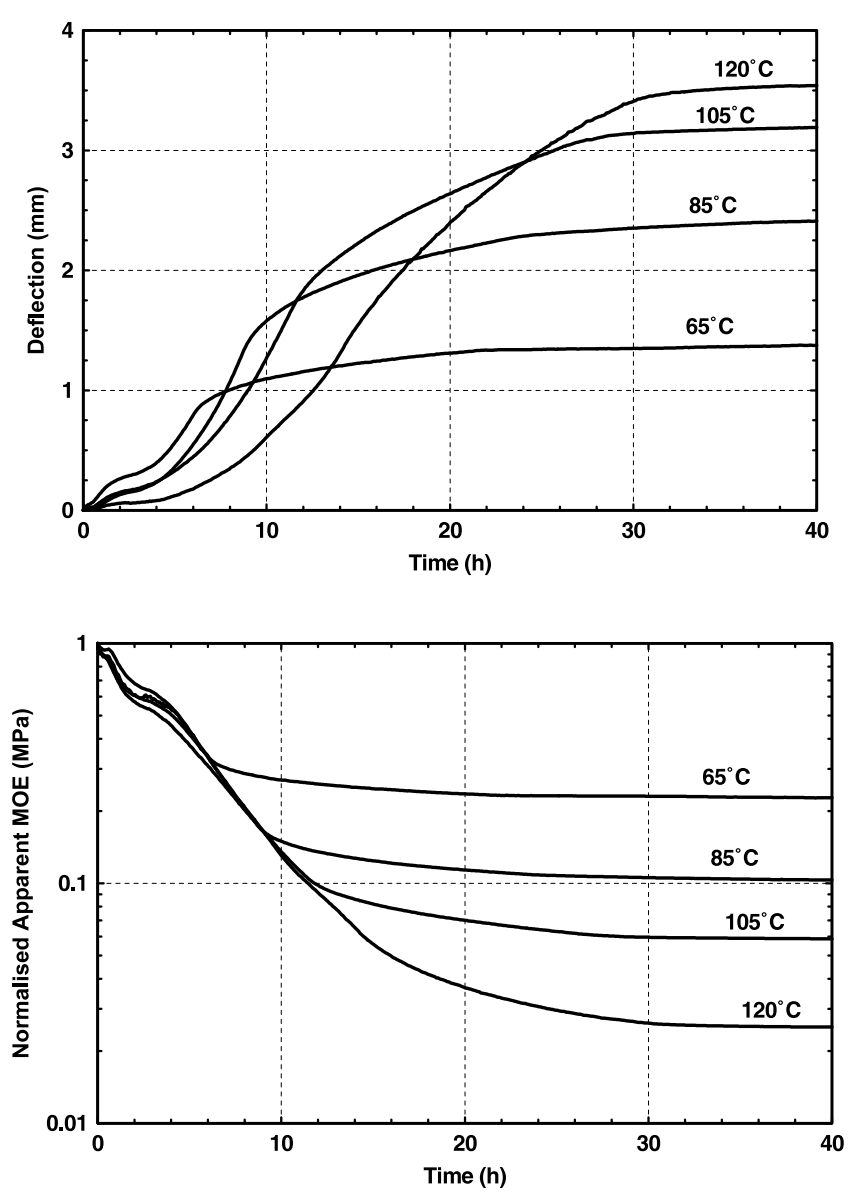

Figure 7. Raw deflection (top) and normalised apparent MOE (bottom) versus time. Tests selected for spruce in radial direction.

One representative example has been selected for each species, each direction and each temperature level. Tables IV and $\mathrm{V}$ synthesise the raw data of the tests selected for spruce and oak respectively. The load, simply ensured by the weight of a chosen mass, varies according to the species, to the test direction and to the temperature plateau. Indeed, the choice of the right mass is quite tricky: it should ensure a deflection suffi-
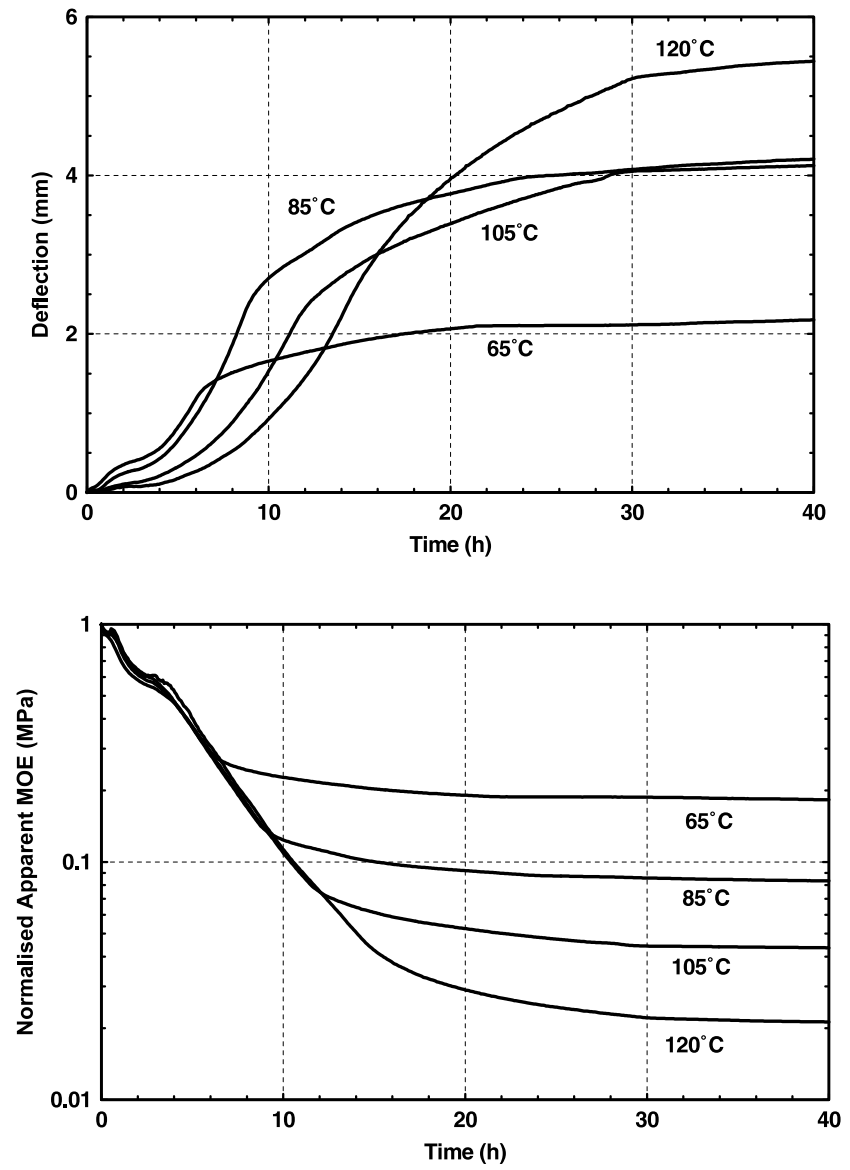

Figure 8. Raw deflection (top) and normalised apparent MOE (bottom) versus time. Tests selected for spruce in tangential direction.

ciently large to be measured accurately and sufficiently low for the deflection to stay within the measuring range throughout the test. The deflection range is mainly limited by the load support surrounding the water container in which each sample is placed. The anisotropy ratio explains why the load is always lower in tangential direction. The required load is lower for spruce at moderated temperature level (spruce is less rigid than oak) but becomes lower for oak at high temperature (the thermal activation is more efficient with this species). As a consequence of this constrain, the maximum stress level is significantly reduced for the tests performed at high temperature. However, remark that these levels remain much lower than the modulus of rupture, which explains why a linear viscoelastic behaviour will be observed when analysing the data. The MOE determined at high temperature is quite homogeneous for the same species and the same direction: about twice as high, for both species, in radial direction compared to the tangential one and much higher for oak than for spruce.

Figures 7 and 8 depict the time evolution of the deflection (raw data, top) and the dimensionless AMOE (AMOE/MOE, bottom) obtained for spruce at $65^{\circ} \mathrm{C}, 85^{\circ} \mathrm{C}, 105^{\circ} \mathrm{C}$ and $120{ }^{\circ} \mathrm{C}$ in radial and tangential directions respectively. Due to the various load levels, the different deflection curves seem quite 

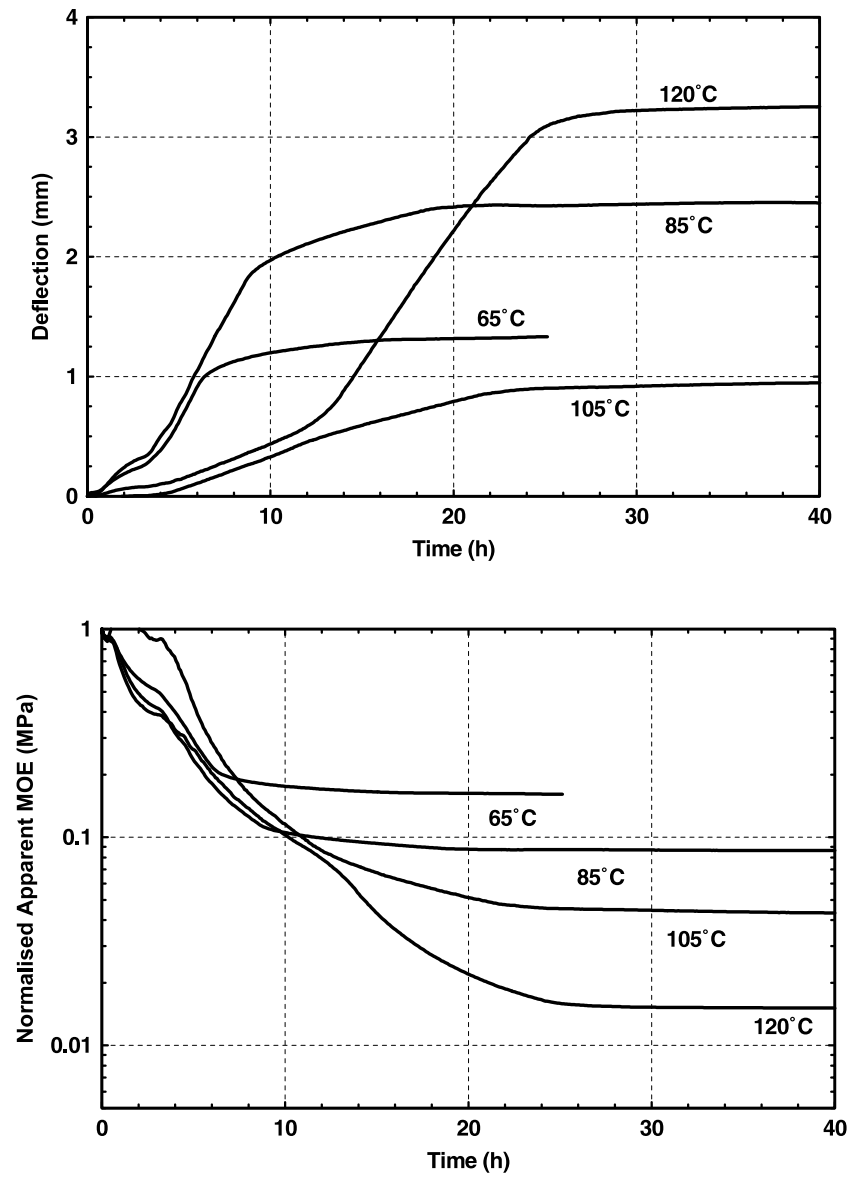

Figure 9. Raw deflection (top) and normalised apparent MOE (bottom) versus time. Tests selected for oak in radial direction.

erratic. However, the calculation of the dimensionless AMOE permits all curves to be properly compared. Note the excellent repeatability of the tests: during the first hours of test, the dimensionless curves of different samples are almost perfectly superimposed while the temperature history of these samples is the same. Keeping in mind that the load level may be very different between two tests, this excellent result proves that the viscoelastic behaviour is linear within the experimental range of stress level. For longer times, a clear effect of the temperature plateau appears, with an asymptotic shape of the normalised apparent MOE. Note also that final normalised values are similar for radial and tangential directions, whatever the plateau temperature. This observation confirms that the ratio of anisotropy is almost kept constant in spite of the thermal activation [18]. The final dimensionless AMOE is just slightly lower in tangential direction.

Figures 9 and 10 depict the same information for the selected tests in the case of oak. The most important trends are similar to those commented for spruce. However, at first glance, one notices that the dimensionless curves are not as nice. In particular, for both directions, the test at $120{ }^{\circ} \mathrm{C}$ depicts a strange shape during the first stage at increasing temperature. We always encountered this problem with oak at high temperature. In fact, due to the dramatic efficiency of thermal activation with
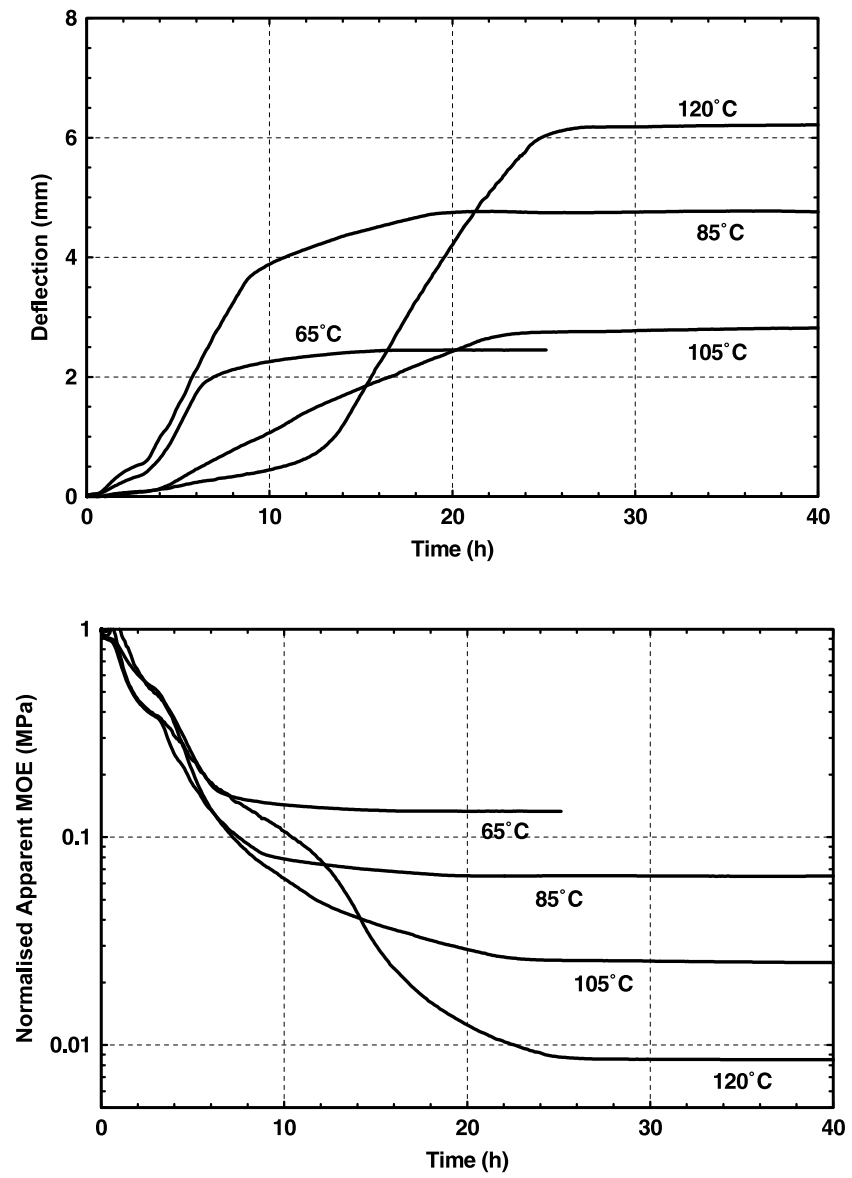

Figure 10. Raw deflection (top) and normalised apparent MOE (bottom) versus time. Tests selected for oak in tangential direction.

oak, the load level has to be ridiculously low for tests at $120^{\circ} \mathrm{C}$. This low stress level allows the thermo-hygro recovery of growth strain to dominate the creep strain while the temperature remains low [9]. Fortunately, the behaviour becomes consistent during the plateau at $120^{\circ} \mathrm{C}$. For the sake of argument, results gathered with tension wood at $120{ }^{\circ} \mathrm{C}$ are exhibited in Figure 11 . In this case, the recovery of growth strain is such that the deflection becomes negative, leading to stupid results when calculating the AMOE, which may be infinite or negative... These problems are intrinsically tied to creep tests, for which the whole history is assumed to be due to the thermal activation of the viscoelastic behaviour. A solution to this problem requires the experimental time to be distinguished from the material time, for example by performing harmonic tests.

The deflection values reported at the end of each test allow the final AMOE to be computed. These values are reported in Figure 12 as a function of the modulus of elasticity measured at room temperature (MOE). In this figure, all successful tests have been plotted: 25 tests for spruce and 19 tests for oak. Spruce (on the left) and oak (on the right) may be simply distinguished by their MOE values. The solid lines represent isovalues of modulus reduction (final AMOE/MOE). Usually, points having the same marker are parallel to these lines, which means that they present the same reduction ratio. Accordingly, 


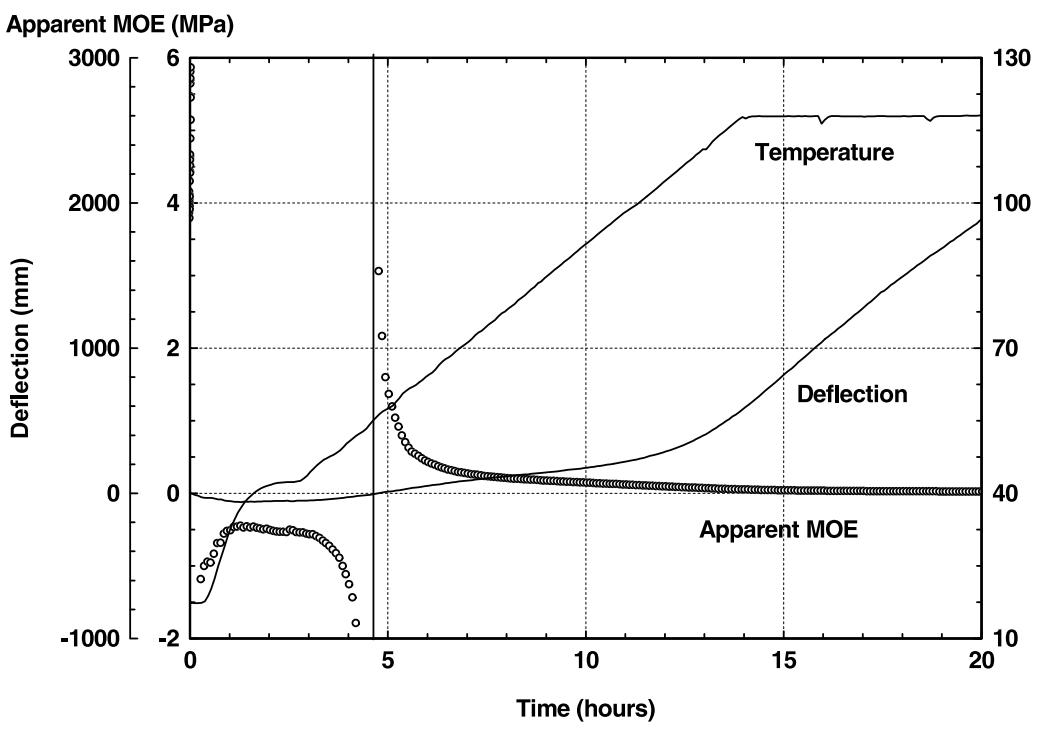

Figure 11. Creep test on oak, tangential direction. This sample is in the tension wood zone. Note the negative deflection due to the recovery of growth strain due to thermal activation, hence the inconsistent negative value of the apparent MOE calculated with these data.

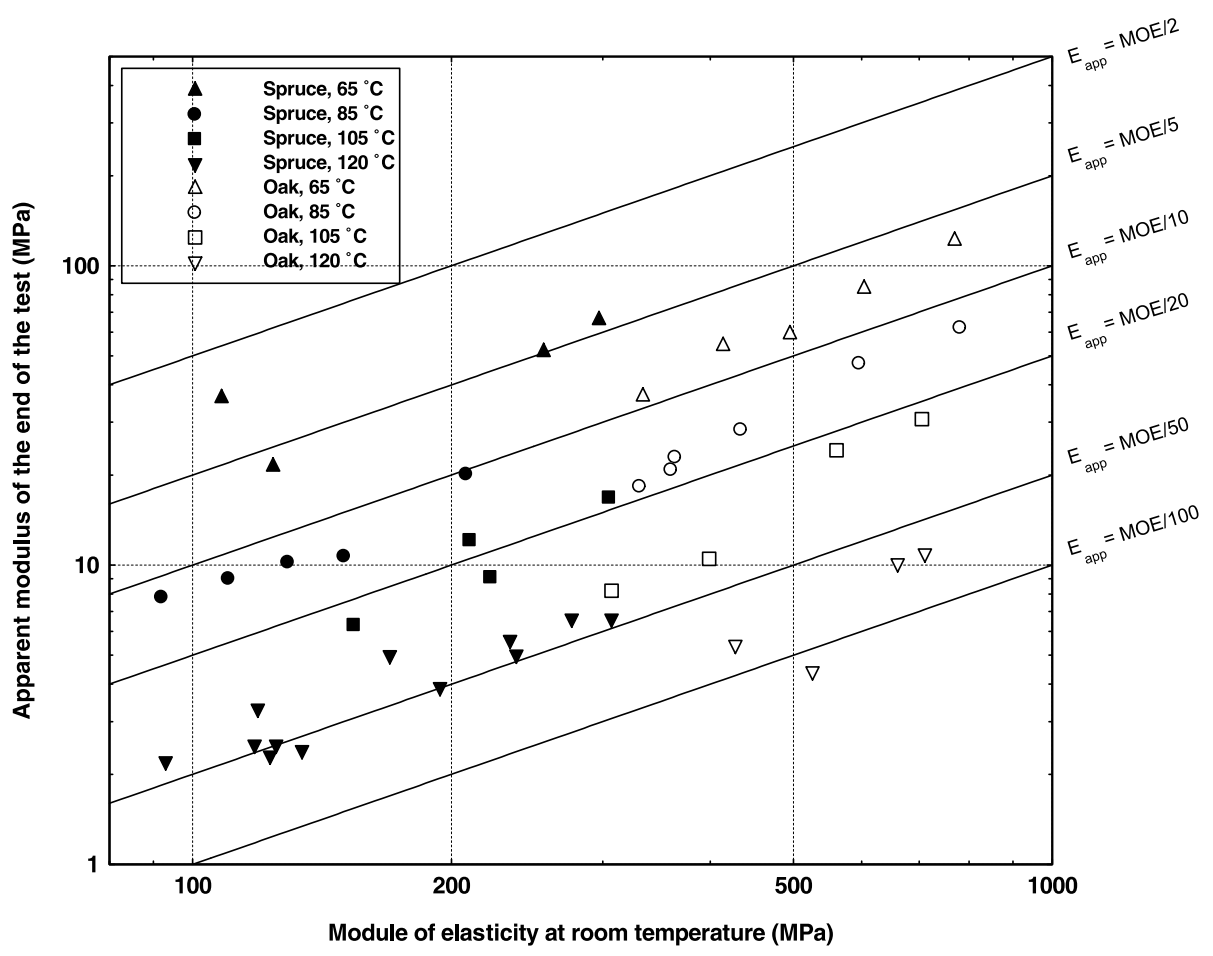

Figure 12. Apparent MOE at the end of each test versus the MOE measured at room temperature before the test. All samples of spruce and oak, in radial and tangential directions for the four levels of plateau temperature.

radial and tangential samples may not be distinguished by this ratio, which is another way to ascertain the isotropic effect of thermal activation (at least in the transverse plane). The temperature effect is obvious; for example, in the case of spruce, the modulus is divided roughly by $5,12,20$ and 50 at $65{ }^{\circ} \mathrm{C}$, $85^{\circ} \mathrm{C}, 105^{\circ} \mathrm{C}$ and $120{ }^{\circ} \mathrm{C}$ respectively. Similarly, one can notice that the thermal activation is stronger for oak, for which the corresponding ratios are higher: approximately 8, 15, 25 and 70 for the same temperature levels. The high ratio attained for this species at $65^{\circ} \mathrm{C}$ (modulus divided by 8 ) proves that the thermal activation is already very efficient at this temperature level, probably thanks to the softening of saturated lignins. The gap between $65^{\circ} \mathrm{C}$ and $85^{\circ} \mathrm{C}$ is higher for spruce than for oak. This confirms that the glass transition temperature is significantly higher for spruce than for oak. This observation confirms most literature data $[8,12]$ and was explained by the difference in ratio S/G (Syningyl units over Guaiacyl units) between softwoods $(S / G=0)$ and hardwoods (S/G up to 1.2$)$ [17].

\section{CONCLUSION}

In this work, we presented an improved experimental set-up capable of performing creep tests on water-saturated samples 
up to $120^{\circ} \mathrm{C}$. The first part of this paper aims at collecting a whole set of experimental data on two species (oak and spruce) in the transverse plane (radial and tangential directions). A typical creep test consists of three phases: a linear increase in temperature up to the desired value, a plateau at this temperature level during $15 \mathrm{~h}$ and a cooling phase. The sample temperature and the deflection are collected continuously during the test. For each species and each direction, a whole set of creep tests is available, at different plateau temperature: $65^{\circ} \mathrm{C}, 85^{\circ} \mathrm{C}$, $105^{\circ} \mathrm{C}$ and $120^{\circ} \mathrm{C}$.

Thanks to a careful sampling, consistent results have been obtained. The modulus of elasticity measured at room temperature confirms the differences expected between oak and spruce and between radial and tangential directions: the MOE is almost twice as high in radial direction and more than twice as high for oak. In the case of oak, the MOE of tension wood can also be distinguished from normal wood: its modulus is smaller in spite of a higher density.

The creep tests reveal the importance of the temperature level on the thermal activation. The later is more efficient for oak than for spruce, while the material direction is hardly noticeable in the transverse section. A whole set of data is now available and will be used in part II of this article to identify the parameters of the constitutive model thanks to an inverse method capable of dealing with several tests simultaneously.

\section{REFERENCES}

[1] Åkerholm M., Salmén L., Interactions between wood polymers studied by dynamic FT-IR spectroscopy, Polymer 42 (2001) 963-969.

[2] Åkerholm M., Salmén L., The oriented structure of lignin and its viscoelastic properties studied by static and dynamic FT-IR spectroscopy, Holzforschung 57 (2003) 459-465.

[3] Bardet S., Gril J., Modelling the transverse viscoelasticity of green wood using a combination of two parabolic elements, C.R. Mécanique 330 (2002) 549-556.

[4] Dwianto W., Morooka T., Norimoto M., Kitajima T., Stress relaxation of sugi (Cryptomeria japonica D. Don) wood in radial compression under high temperature steam, Holzforschung 53 (1999) 541-546.

[5] Dwianto W., Morooka T., Norimoto M., Compressive creep of wood under high temperature steam, Holzforschung 54 (2000) 104-108.

[6] Ebrahimzadeh P.R., Kubat D.G., Effects of humidity changes on damping and stress relaxation in wood, J. Mater. Sci. 28 (1993) $5668-5674$.

[7] Genevaux J.-M., Le fluage à température linéairement croissante: caractérisation des sources de viscoélasticité anisotrope du bois, Thèse de Doctorat de l'Institut Nationnal Polytechnique de Lorraine, Nancy, France, 1989.

[8] Göring D.A.I., Thermal softening of lignin, hemicellulose and cellulose, Pulp Pap. Mag. Can. 64 (1963) T517-T527.

[9] Gril J., Berrada E., Thibaut B., Recouvrance hygrothermique du bois vert. II. Variations dans le plan transverse chez le châtaignier et l'épicéa et modélisation de la fissuration à cœur provoquée par l'étuvage, Ann. Sci. For. 50 (1993) 487-508.

[10] Guitard D., Mécanique du matériau bois et composites, Cepadues éditions, Toulouse, 1987.

[11] Hanhijärvi A., Deformation properties of Finnish spruce and pine wood in tangential and radial directions in association to high temperature drying. Part II. Experimental results under constant conditions (viscoelastic creep), Holz Roh- Werkst. 57 (1999) 365-372.

[12] Irvine G.M., The glass transitions of lignin and hemicellulose and their measurements by differential thermal analysis, TAPPI J. 67 (1984) 118-121.

[13] Kelley S.S., Rials T.G., Glasser W.G., Relaxation behaviour of the amorphous components of wood, J. Mater. Sci. 22 (1987) 617-624.

[14] Kollmann F.P., Côté W.A., Principles of Wood Science and Technology, Vol. 1, Solid Wood, Springer-Verlag, 1968.

[15] Le Govic C., Hadjhamou A., Rouger F., Felix B., Modélisation du fluage du bois sur la base d'une équivalence Temps-Température, Actes du $2^{\mathrm{e}}$ colloque Sciences et Industries du bois, A.R.B.O.L.O.R. Nancy, France, 1988, pp. 349-356

[16] Maeda H., Fukada E., Effect of bound water on piezoelectric, dielectric and elastic properties of wood, J. Appl. Polym. Sci. 33 (1987) 1187-1198.

[17] Olsson A.-M., Salmén L., Viscoelasticity of in situ lignin as affected by structure, softwood vs. hardwood, ACS Symposium Series No. 489, Am. Chem. Soc., 1992, pp. 133-143.

[18] Ostberg G., Salmen L., Terlecki J., Softening temperature of moist wood measured by differential scanning calorimetry, Holzforschung 44 (1990) 223-225.

[19] Passard J., Perré P., Creep tests under water-saturated conditions: do the anisotropy ratios of wood change with the temperature and time dependency ? 7th International IUFRO Wood Drying Conference, Tokyo, Japan, 2001, pp. 230-237.

[20] Perré P., Aguiar O., Fluage du bois "vert" à haute température $\left(120^{\circ} \mathrm{C}\right)$ : expérimentation et modélisation à l'aide d'éléments de Kelvin thermo-activés, Ann. For. Sci. 56 (1999) 403-416.

[21] Ranta-Maunus A., The viscoelasticity of wood at varying moisture content, Wood Sci. Technol. 9 (1975) 189-205.

[22] Salmen L., Viscoelastic properties of in situ lignin under watersaturated conditions, J. Mater. Sci. 19 (1984) 3090-3096.

[23] Schniewind A.P., Recent progress in the study of the rheology of wood, Wood Sci. Technol. 2 (1968) 188-206.

[24] Schniewind A.P., Barrett J.D., Wood as linear orthotropic viscoelastic material, Wood Sci. Technol. 6 (1972) 43-57.

[25] Swensson S., Toratti T., Mechanical response of wood perpendicular to grain when subjected to changes of humidity, Wood Sci. Technol. 36 (2002) 145-156.

[26] Timoshenko S.P., Résistance des matériaux, Bordas, Paris, France, 1968.

[27] Tsujiyama S., Miyamori A., Assignment of DSC thermograms of wood and its components, Thermochim. Acta 351 (2000) 177-181.

[28] Wheeler E.A., Baas P., Gasson P.E., IAWA list of microscopic features for hardwood identification, IAWA Bull. 10 (1989) 219-332. 